\title{
Understanding drought responses of sugarcane cultivars controlled under low water potential conditions
}

\author{
Chanoknat Chapae ${ }^{1}$, Patcharin Songsri ${ }^{1,2}$, Santimaitree Gonkhamdee ${ }^{1,2}$, and Nuntawoot Jongrungklang ${ }^{1 *, 2}$ \\ ${ }^{1}$ Khon Kaen University, Faculty of Agriculture, Muang, Khon Kaen 40002, Thailand. *Corresponding author (nuntawootjrk@gmail.com). \\ ${ }^{2}$ Khon Kaen University, Northeast Thailand Cane and Sugar Research Center, Muang, Khon Kaen 40002, Thailand.
}

Received: 26 November 2019; Accepted: 19 March 2020; doi:10.4067/S0718-58392020000300370

\begin{abstract}
Drought resistance mechanisms of sugarcane (Saccharum officinarum L.) vary with different conditions and locations. Understanding physiological and morphological responses of sugarcane cultivars grown under uniform and controllable conditions needs to be established. Therefore, the objective of this study was to investigate the mechanisms of drought responses of sugarcane cultivars grown under low water potential conditions via polyethylene glycol (PEG) induction. The hydroponic experiment was conducted under open greenhouse conditions. A split-plot in a randomised complete block design with three replicates was used. The PEG rates $(0 \%$ and $1 \%)$ were assigned as main factor. Six sugarcanes cultivars differing in drought-resistance levels were sub-plot factors. To understand drought mechanisms, physiological and morphological traits were measured during stress and recovery periods. Drought mechanisms clearly evidenced only low water potentials at early growth stages, but not terminal drought stress. The six cultivars used in this study could be classified into two groups based on responses of shoot mass after exposure to early drought, consisting of reduced shoot dry weight when exposed to early drought stress and insensitive to early drought stress. In recovery phase, shoot DM of reduced shoot dry weight cultivar ('KKU99-03') was 754.6 and $499.5 \mathrm{~g} \mathrm{pl}^{-1}$ under control and PEG treatments, respectively, whereas shoot DM of insensitive group did not differ from control conditions. Drought resistance mechanisms, which can maintain aboveground DM of sugarcane cultivars under this condition, varied. Good adaptations for maintenance shoot mass under hydroponics were photosynthesis, stomatal conductance, partitioning of dry weight, root dry weight and green leaf number proportions. The ability to perform well with acclimation of these traits might be useful for improving drought resistance genotypes in the future.
\end{abstract}

Key words: Hydroponics, leaf dry weight, leaf water potential, osmoticum, stalk dry matter.

\section{INTRODUCTION}

Drought, which is one of the most serious of the environmental problems, plays an important role in reducing the yields of many crops (Meher et al., 2017). Most production areas of sugarcane (Saccharum officinarum L.) in the world are in rain-fed conditions, so the crop has a chance of experiencing water deficits. Drought can reduce sugarcane yield up to $80 \%$ (Singh and Gururaja Rao, 1987), so this is a serious problem under production processing. There are various strategies to solve this obstacle, such as providing water for irrigation and usage drought tolerant cultivars. The second choice seems to be sustainable for producing cane under drought conditions. The use of drought-resistant sugarcane varieties can avoid and reduce drought damage, which affects cane yield under dehydration conditions (Medeiros et al., 2013). The responses of physiological and morphological characteristics are identified as selection criteria for drought-resistant sugarcane cultivars (Smit and Singels, 2006). 
Variations in the responses of physiological traits have been reported in the literature. In field experiments, SPAD chlorophyll meter reading (SCMR) and chlorophyll fluorescence of sugarcane decreased when subject to drought stress conditions (Silva et al., 2011; Zhao et al., 2012; Begum et al., 2012; Jaiphong et al., 2016). However, SCMR and chlorophyll fluorescence did not respond to water deficits in pot conditions (Khonghintaisong et al., 2018). The variation of physiological and morphological traits might be due to different soil environments and conditions. The heterogeneity of soil particles affects moisture and nutrient infiltrations as well as root penetration. Therefore, the understanding of physiological and morphological responses of sugarcane cultivars grown under uniform and controllable conditions needs to be established. Planting using soilless media is a technology that can effectively control for various soil-related factors (Wahome et al., 2011; Trejo-Téllez and Gómez-Merino, 2012). This method can also control the uniformity of nutrient application, and it can be conducted without weed, insect and disease problems.

Hydroponics is a controllable planting system with uniform media, and it has been used in several studies (Girdthai et al., 2010; Ayalew et al., 2015; Gashgari et al., 2018). Hydroponics systems can be operated in temperature- and lightcontrolled greenhouses, which allow crop production throughout all seasons (Shavrukov et al., 2012). Currently, the hydroponics system is one of the standard methods that are widely used in both commercial and industrial applications (Shavrukov et al., 2012; Nguyen et al., 2016). In sugarcane, previous reports found a positive correlation between root traits, i.e. root length and root dry weight derived from hydroponics, and root length density (RLD) from field conditions (Chapae et al., 2019). Chapae et al. (2019) also reported that hydroponic cultivation could be an alternative approach for investigating root and shoot traits.

Drought stress investigations under hydroponic conditions have been conducted in wheat, millet, rice, barley and cabbage (García-Morales et al., 2012; O’Donnell et al., 2013; Robin et al., 2015; Amist and Singh, 2016; Hellal et al., 2018). For those previous reports, polyethylene glycol (PEG) was used to decrease the osmotic potential, thus inducing plant dehydration. To date, there is no report on the physiological and morphological responses of sugarcane cultivars conducted with PEG to mimic low water potential conditions. The understanding of physiological and morphological responses to drought of sugarcane cultivars grown under hydroponic conditions is necessary, as it would clearly explain the mechanisms for drought resistance of sugarcane. Therefore, the objective of this study was to investigate the mechanisms of drought responses of sugarcane cultivars grown under low water potential conditions at both early and late growth stages via PEG induction. This information will be useful for further work by providing a basic knowledge of resistance mechanisms against drought conditions.

\section{MATERIALS AND METHODS}

Regarding the sugarcane (Saccharum officinarum L.) production system in the tropical zone, the crop is usually grown from October to November. In these conditions, sugarcane often suffers drought during the dry season at an early growth stage; around 5 mo after planting; tillering phase (Ramesh and Mahadevaswamy, 2000); due to lack of rainfall from December to April. In addition, sugarcane also experiences water shortages during the rainy season intermittently at 7-8 mo after planting. Regarding the water stress, it may affect cane at the stem elongation phase to the mature phase (Ramesh and Mahadevaswamy, 2000). Hence, this experiment was conducted to mimic drought, as the natural condition would have occurred in tropical areas.

\section{Plant material and experimental design}

The hydroponic experiment was conducted under open greenhouse conditions at the Field Crop Research Station of Khon Kaen University, Khon Kaen (16 $28^{\prime}$ N, 102 $48^{\prime}$ E; 200 m a.s.l.), Thailand, from November 2017 to November 2018. Both drought periods were examined separately. The aeration system was the dynamic root floating technique (DRFT) (Chapae et al., 2019). A split-plot in a randomised complete block design with three replicates was used. Polyethylene glycol (PEG) application rates, such as $0 \%$ and $1 \%$ PEG were assigned as a main factor. Six sugarcane cultivars, namely 'Kps01-12', 'KK3', 'KKU99-02', 'KKU99-03', 'UT12' and 'UT13', which differed in their drought-resistance levels, were assigned to sub-plots. 


\section{Experimental management}

Ten months after planting, cane stalks were cut into single budded sets for using in this experiment. A budded set was planted and irrigated immediately to obtain uniform germination. Cane seedlings were transplanted to the hydroponic system at $10 \mathrm{~d}$ after planting (DAP). Each hydroponic block was $70 \mathrm{~cm}$ wide $\times 320 \mathrm{~cm}$ length, with a depth of $30 \mathrm{~cm}$. A block contained six cane seedlings, arranged in two rows, with three plants per row. The spacing of each plant was $30 \times 80$ $\mathrm{cm}$. The hydroponic system was filled with water that had a pH of 7.05 and an electrical conductivity (EC) of $0.8 \mathrm{dS} \mathrm{m}^{-1}$. Liquid fertiliser was applied as either an $\mathrm{A}$ or B mix with water, and the $\mathrm{EC}$ rate controlled at $4.0 \mathrm{dS} \mathrm{m}^{-1}$ (4 L liquid fertiliser $300 \mathrm{~L}^{-1}$ water). Fertiliser solution (total volume $50 \mathrm{~L}$ ) mix A included $5.5 \mathrm{~kg} \mathrm{CaNO}_{3}^{-}$and $80 \mathrm{~g}$ Fe-EDTA, and B solution was mixed from $435 \mathrm{~g} \mathrm{NH}_{4} \mathrm{H}_{2} \mathrm{PO}_{4}, 5 \mathrm{~kg} \mathrm{KNO}_{3}, 2.82 \mathrm{~kg} \mathrm{MgSO}_{4}^{-}, 875 \mathrm{~g} \mathrm{KPO}_{4}^{-}, 2 \mathrm{~g} \mathrm{Cu}, 5.5 \mathrm{~g} \mathrm{Zn}$ and $9 \mathrm{~g}$ Mn-EDTA. Insect and disease controls were performed as necessary to keep the plants free from pests throughout the experimental period.

For control treatments, the solution media did not apply PEG throughout the studied period, and water was added in the solution as the same content with PEG treatment. In the PEG applications, the osmoticum was applied at 40 DAP, and gradually added at 10-d intervals at a rate of $0.083 \%$ until 150 DAP (1.00\% PEG content). After 150 DAP, for PEG application treatment, the PEG mixed with solution was removed and instead the plants were provided same normal solution as the control treatment. For osmotic stress at the elongation phase, PEG was given to sugarcane at 7 mo after planting (210 DAP) and it was done the same way as the first water deficit trial and continued until 310 DAP. Recovery conditioning was then done with normal nutrient solution until harvest.

\section{Data collections}

Relative humidity (RH), evaporation (E0) and maximum and minimum temperatures were recorded daily, from the time of transplanting until data collection was finished (around $360 \mathrm{~d}$ after transplanting) by a weather station located at a distance of $10 \mathrm{~m}$ from the experimental area. The maximum air temperature range was $39-40{ }^{\circ} \mathrm{C}$, and the minimum temperature ranged $9.0-22.5^{\circ} \mathrm{C}$, during the experimental period. Both air temperatures had a similar pattern, with low values during the early investigational period that then increased during the middle and terminal periods (Figure 1). The E0 (range 3.57$5.84 \mathrm{~mm}$ ) and RH (range 61\%-98\%) revealed that normal conditions occurred during this experimental period (Figure 1). Therefore, meteorological conditions should not have disturbed the normal growth of sugarcane in this study.

\section{Above-ground characteristics}

Stem heights were measured at $0 \%, 0.17 \%, 0.33 \%, 0.50 \%, 0.67 \%, 0.83 \%$ and $1.00 \%$ PEG in water content in the container and $1 \mathrm{mo}$ after the recovery period. Stem height was measured from the base of stem to the last dewlap.

At $1.00 \%$ PEG in both trials, destructive samples were cut pieces and separate shoot and root parts. For shoot data, leaves and stalks of each sample were manually separated. Leaves were then sampled with $10 \%$ of the total leaves to determine leaf area. Shoot dry weight was determined separately from stems and leaves using oven drying at $80{ }^{\circ} \mathrm{C}$ for 48 $\mathrm{h}$ or until constant weight. Root dry weight was measured only for the early drought stress trial by drying with a sample incubator at $80^{\circ} \mathrm{C}$ for $48 \mathrm{~h}$ or until a constant dry weight.

Figure 1. Relative humidity, evaporation, and maximum (T-max) and minimum (T-min) temperatures during the experimental period at the meteorological station, Khon Kaen University, Thailand.

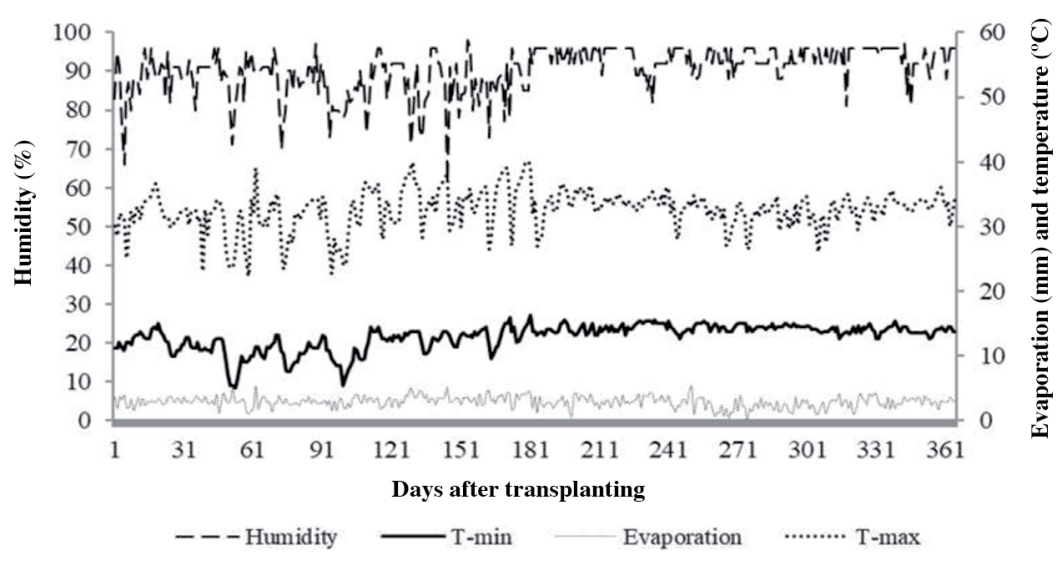




\section{Physiological data}

Chlorophyll fluorescence was collected using a Mini-PAM portable fluorometer (PAM-2000, Heinz Walz GmbH, Effeltrich, Germany). A dark leaf clip was installed $15 \mathrm{~min}$ before measuring the data, and the second to third fully extended leaf from the top of main stem was a leaf sample. SPAD chlorophyll meter reading (SCMR) was measured via the SPAD-502 chlorophyll meter (SPAD-502, Minolta, Tokyo, Japan), which measured the same leaf position with a chlorophyll fluorescence measurement. Green and brown leaf numbers were also counted and compared between PEG and non-PEG treatments. All three non-destructive samples were done at $0 \%, 0.17 \%, 0.33 \%, 0.50 \%, 0.67 \%, 0.83 \%$ and $1.00 \%$ PEG application 1 and 2 mo after the recovery period.

At $0.67 \%$ PEG, photosynthesis rate and stomatal conductance were measured at the second fully extended leaf from the top of main stem using a portable photosynthesis system (LI-6400XT, LI-COR, Lincoln, Nebraska, USA). The measurements were done between 10:00 and 12:00 h.

For destructive samples, leaf water potential (LWP) was conducted with a pressure bomb device (Model 3005F01, Soil moisture Equipment Corporation, Santa Barbara, California, USA), collecting at 0\%, 0.50\% and 1.0\% PEG 1 and 2 mo after recovery. The second and third fully extended leaves from the top of main stem were cut and processed between 10:00 and 12:00 h.

\section{Statistical analysis}

In both drought stress conditions, the statistical analysis was separately conducted using the Statistix 8 software program version 8.0 (Analytical Software, Tallahassee, Florida, USA). The measured data were subjected to ANOVA, according to a split-plot in a randomised complete block design. The means comparison was based on the least significant difference test (Gomez and Gomez, 1984).

\section{RESULTS AND DISCUSSION}

\section{Leaf water status under PEG treatment}

Water status in leaves was represented by LWP. The results show that water deficits at early growth stage of all sugarcane varieties clearly responded to low water potential solution, whereas terminal drought did not affect LWP (Figure 2). For both kinds of drought, LWP values of all genotypes were recovered after the removal of PEG. According to the current data, it seems likely that drought stress late in the sugarcane season would have a slight effect due to the nearly physiologically mature stage. Therefore, the explanation of this result mainly focuses on the water deficit at early growth stage.

There was no report of drought studies conducted with sugarcane under hydroponics. Nevertheless, related results were found, soybean LWP was significantly reduced from -0.7 to $-2.2 \mathrm{MPa}$ when subjected to drought stress via low water potential (Ohashi et al., 2008). Additionally, in rice susceptible cultivars, LWP values induced by $14 \mathrm{~d}$ of drought stress under hydroponics revealed low values compared with the control treatment, and increased their values after recovery (Larkunthod et al., 2018).

\section{Responses of root under PEG treatment}

In terms of root dry weight, 'UT12', 'KKU99-02' and 'KKU99-03' had significant differences between control and PEG treatments, including reduction of roots dry weight (Figure 3i). Good responses to early drought stress were shown by 'UT13', 'Kps01-12' and 'KK3'; they showed roots the same dry weight as the normal condition (Figure 3i).

\section{Root characteristic for drought resistant, affected via PEG}

Roots play an important role in drought resistance in sugarcane (Jangpromma et al., 2012). A large root system is a key trait for drought resistance in sugarcane (Smith et al., 2005; Jangpromma et al., 2012). Dehydration affects the development of plant roots (Smit and Singels, 2006). Root length, surface area, and dry weight among sugarcane cultivars vary significantly when drought occurs in short (Jangpromma et al., 2012) and long periods (Khonghintaisong et al., 2018) under pot conditions. Root characteristics were significantly different among hybrid rice grown under hydroponics (Rajkumar and Ibrahim, 2014). PEG induced drought stress under hydroponic experimental conditions in cabbage with decreased root dry weight (Amist and Singh, 2016). 
Figure 2. Leaf water potential of six sugarcane cultivars (UT13, KK3, Kps01-12, KKU99-02, KK3 and KKU99-03) at polyethylene glycol (PEG) treatments and control treatments for early drought (a-f) and for terminal drought (g-l), under hydroponic system.

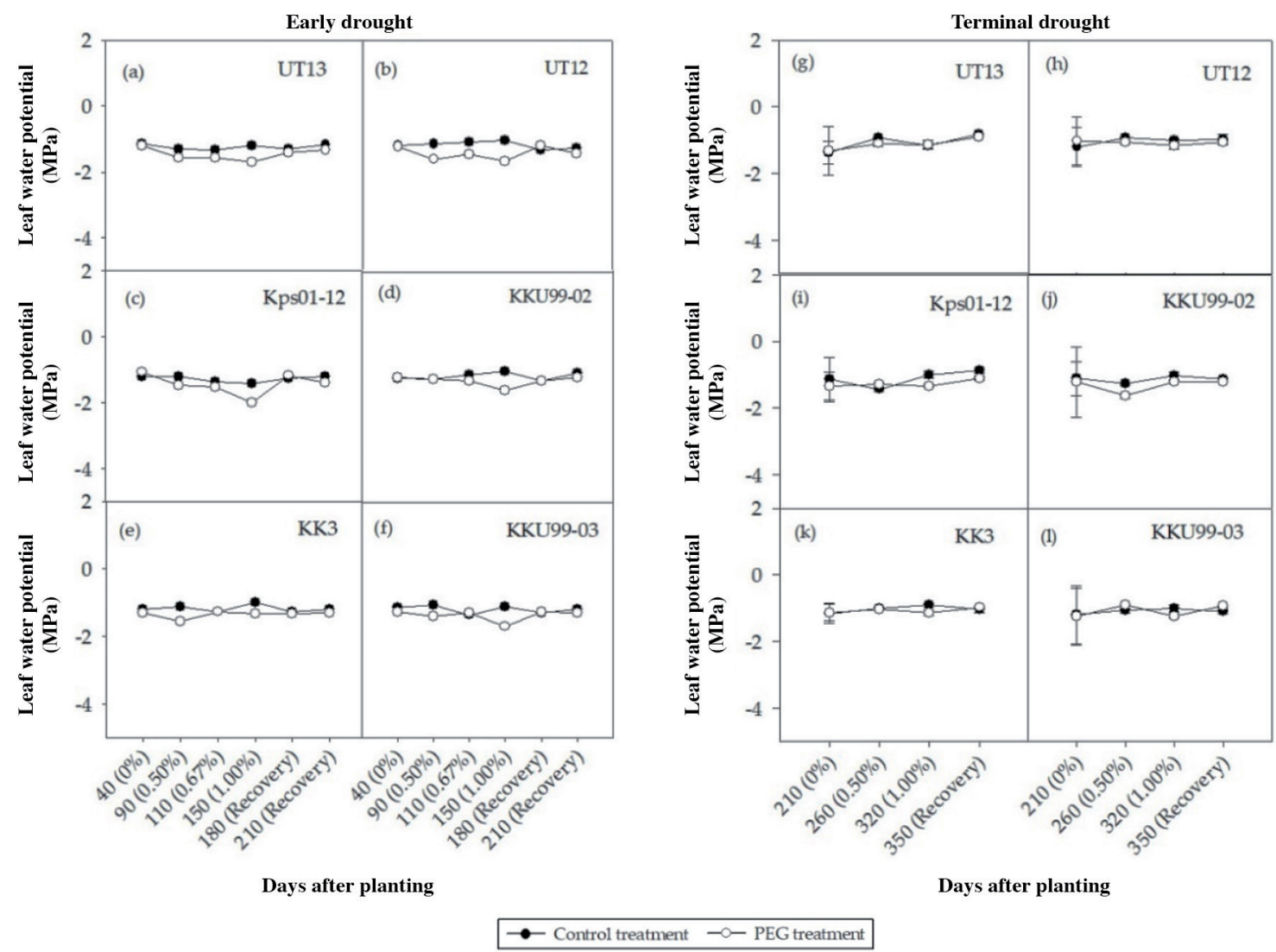

Vertical bars show standard error difference of means.

\begin{abstract}
Above-ground traits
At the highest rate of PEG application, leaf area indices and leaf dry weights of all sugarcane genotypes used in this research had significant differences between control and PEG treatments in the early drought trial. This revealed that low water potentials induce the limitation of leaves for all cultivars. For the data of $60 \mathrm{~d}$ after recovery (DAR) in the early drought trial, 'UT13', 'Kps01-12' and 'KK3' had a higher leaf area in PEG treatments than under normal conditions. Additionally, higher leaf dry weights occurred in 'Kps01-12' and 'KKU99-03' (Figures 3a, 3b, 3c, 3d, and 4). For the late drought trial, there were no differences in leaf area at the highest PEG-treated conditions, while 'UT13', 'KK3' and 'KKU99-02' had high values of leaf area during the recovery period when compared with the normal conditions (Figure $3 \mathrm{a}$ and $3 \mathrm{~b}$ ). In addition, throughout the PEG and recovery phases, leaf dry mass was not different between the control and the PEG treatments (Figure $3 \mathrm{c}$ and $3 \mathrm{~d}$ ).

The reduction of the leaf area is a prior characteristic, when damaged from water dehydration; its reduction is a rapid response to drought by decreasing water loss by transpiration (Taiz and Zeiger, 2002). 'Kps01-12' showed a good adaptation of enhancing leaf traits after removing the water stress via osmoticum. In sugarcane, there has been a lack of research under hydroponics, even though drought is identified as a main factor to reduce leaf area under field (Begum et al., 2012; Zhao et al., 2012) and pot conditions (Patade et al., 2011). However, the responses for leaf area have varied among different genotypes and drought intensities (Endres et al., 2018). Drought tolerant research on cowpeas grown in a hydroponics system was reported by Ogbonnaya et al. (2003), who found that drought-resistant varieties could better maintain leaf area than a susceptible variety. Sizes and numbers of leaves were decreased in forage sorghum at $4 \mathrm{wk}$ after treatment with PEG in hydroponics (O’Donnell et al., 2013).
\end{abstract}


Figure 3. Leaf area index, leaf dry weight, stalk dry weight, root dry weight, and shoot dry weight for early drought and after $60 \mathrm{~d}$ recovery period of six sugarcane cultivars at polyethylene glycol (PEG) treatments and control treatments, under hydroponic system.

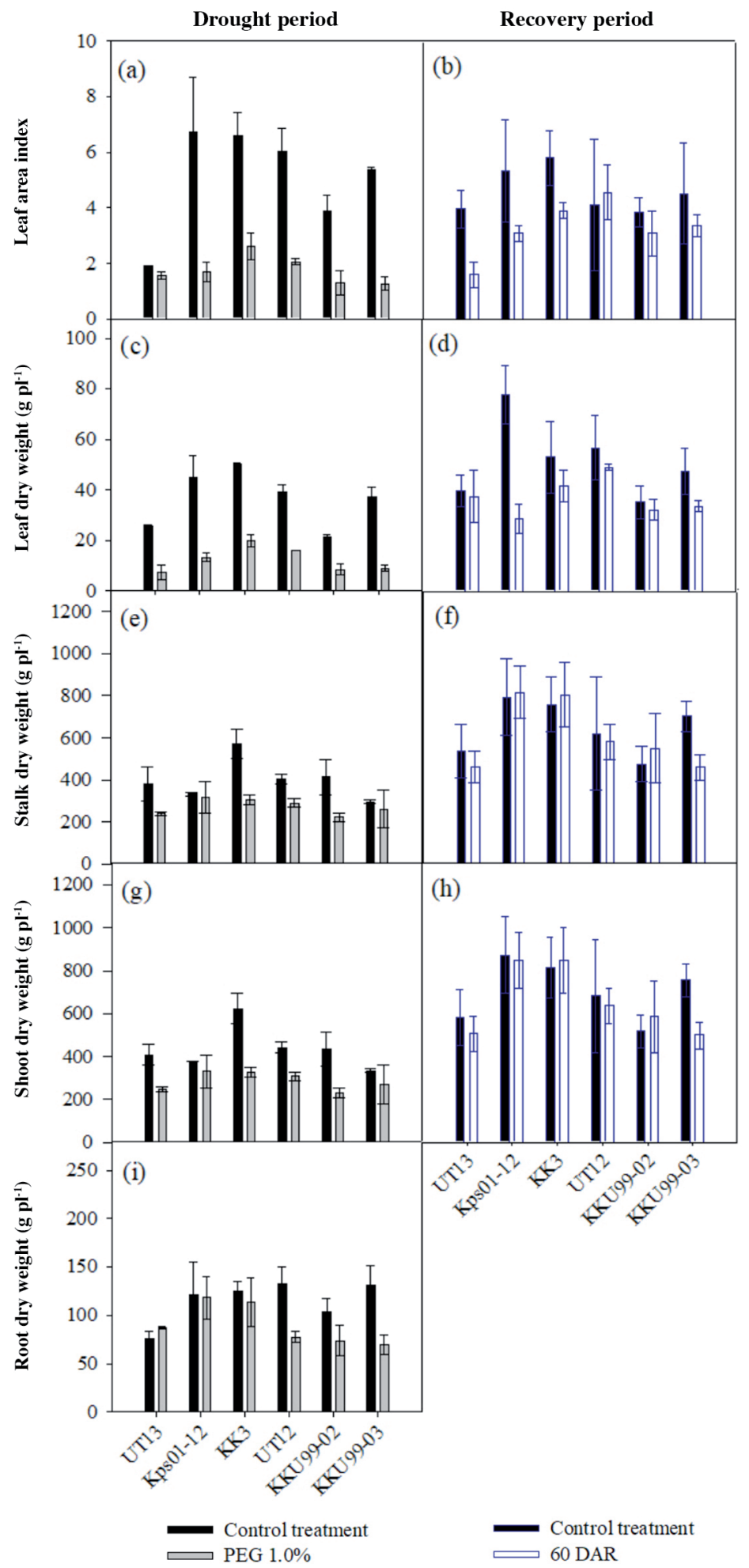

Vertical bars show the standard error of the differences of means. 
Figure 4. Six sugarcane cultivars grown under polyethylene glycol (PEG) treatment and control treatment (non-PEG).

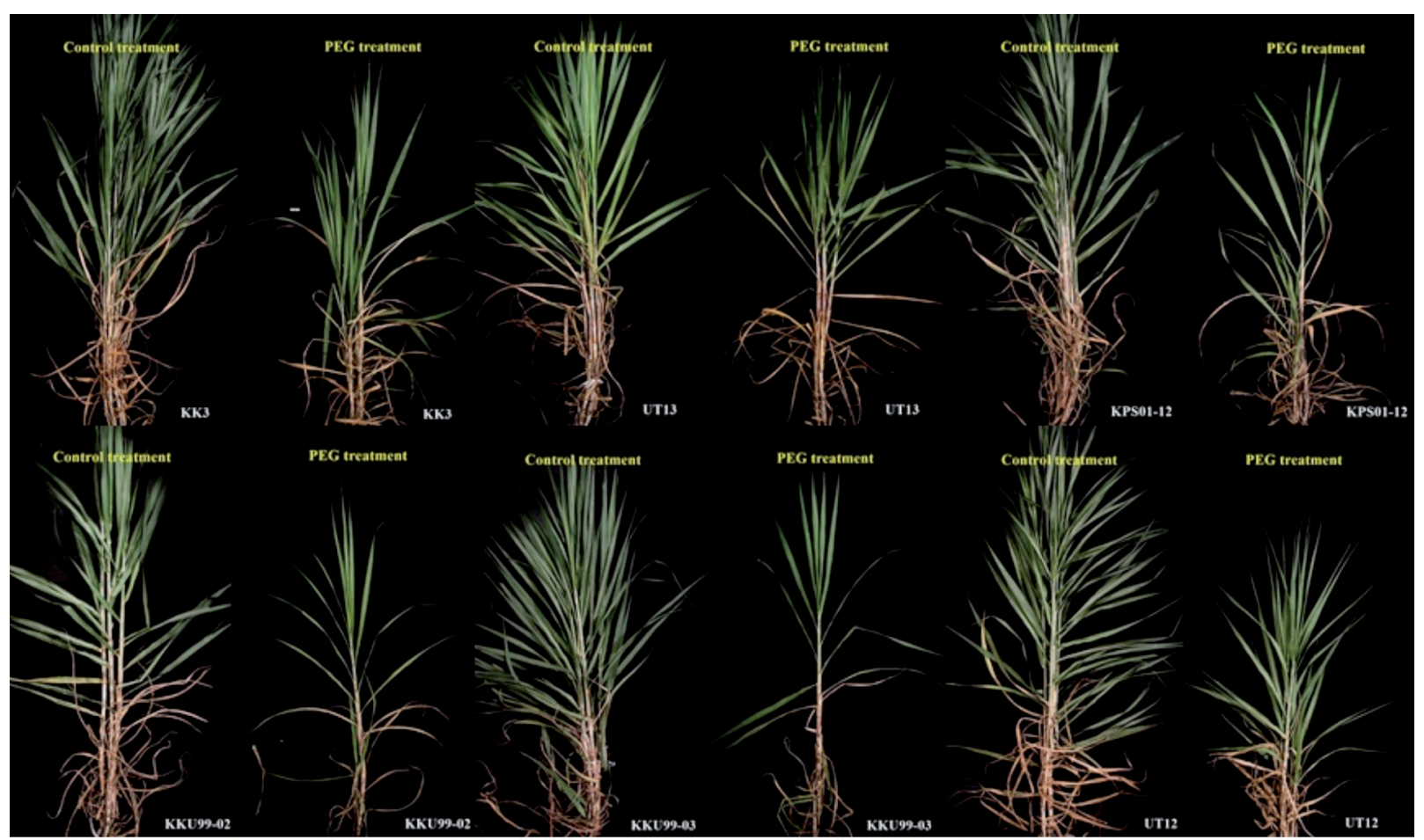

For stalk DM, 'UT13', 'KK3', 'UT12' and 'KKU99-02' in PEG treatments had smaller stalks than these cultivars under normal conditions, while 'Kps01-12' and 'KKU99-03' were unresponsive. In the recovery period, 'KKU99-03' had lower leaf, stalk and shoot DM (Figure 3d, f, and h). After remove PEG shoot DM of 'KKU99-03' under control and PEG treatments were 754.6 and $499.5 \mathrm{~g} \mathrm{pl}^{-1}$, respectively, but other cultivars were not different. Under the effect of PEG, all cultivars had a reduction of stem height. However, 'UT13', 'UT12' and 'KKU99-02' could recover to the normal height compared to non-PEG treatment, but 'KKU99-03', 'KK3' and 'Kps01-12' could not (Figure 5). There was compensation between height and stalk dry weight for 'KK3' and 'Kps01-12', which showed lower heights while maintaining stalk weights.

\section{Above-ground traits under PEG treatment}

Cane grown under appropriate conditions had a higher total DM than those grown under prolonged drought conditions (Jaiphong et al., 2016). Shoot traits of rice cultivars were significantly different among cultivars, and they could be grouped based on the traits for drought tolerance (Rajkumar and Ibrahim, 2014). Rice had responses to drought under hydroponics, such as decreases in DM and shoot length (Larkunthod et al., 2018), and similar responses were found in wheat (Raziuddin et al., 2010; Robin et al., 2015).

\section{Drought tolerance mechanism of sugarcane under hydroponics}

In this research, the six sugarcane genotypes could be mainly classified into two groups namely: 1) reduced shoot dry weight when experiencing early drought stress and 2) insensitive to drought stress in terms of shoot dry weight. The first type consisted of only one cultivar, KKU99-03. This genotype had low green leaf numbers (Figure 6b) and low leaf and root dry weights during drought stress (Figures $3 \mathrm{c}$ and 3i), and a reduction in stalk mass (Figure 3e). Despite unresponsive single leaf photosynthesis and transpiration (Figures $7 \mathrm{a}$ and $7 \mathrm{~b}$ ), in terms of canopy photosynthesis, assimilation of all sources by leaves in the canopy was very limited. It seems likely that the 'KKU99-03' genotype invested the limited sugar from fixed $\mathrm{C}$ to stalks, not to roots and leaf organs. Hence, shoot mass under early drought stress did not respond, or responded in a way opposite from with root and leaf organs. In addition, at the recovery phase, foods from photosynthesis were used for leaves, resulting in reduced stalk heights (Figure 5f) and dry weights (Figure 3f). 
Figure 5. Stalk height of six sugarcane cultivars (UT13, KK3, Kps01-12, KKU99-02, KK3 and KKU99-03) with polyethylene glycol (PEG) and control treatments for early (a-f) and terminal drought (g-l), under hydroponic system.

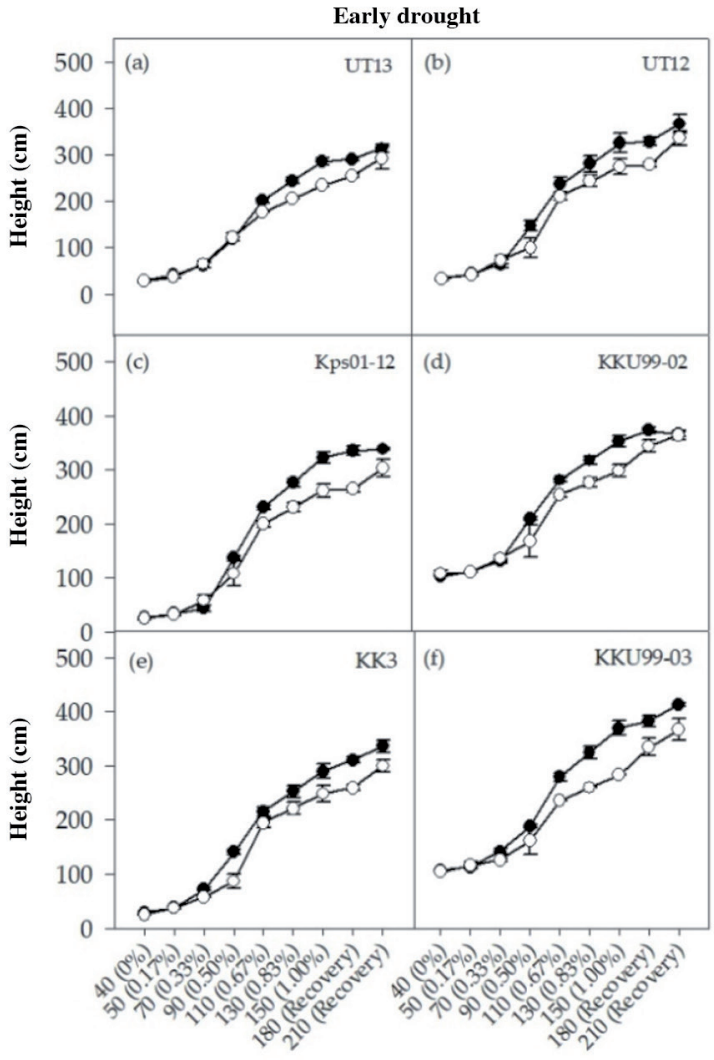

Days after planting

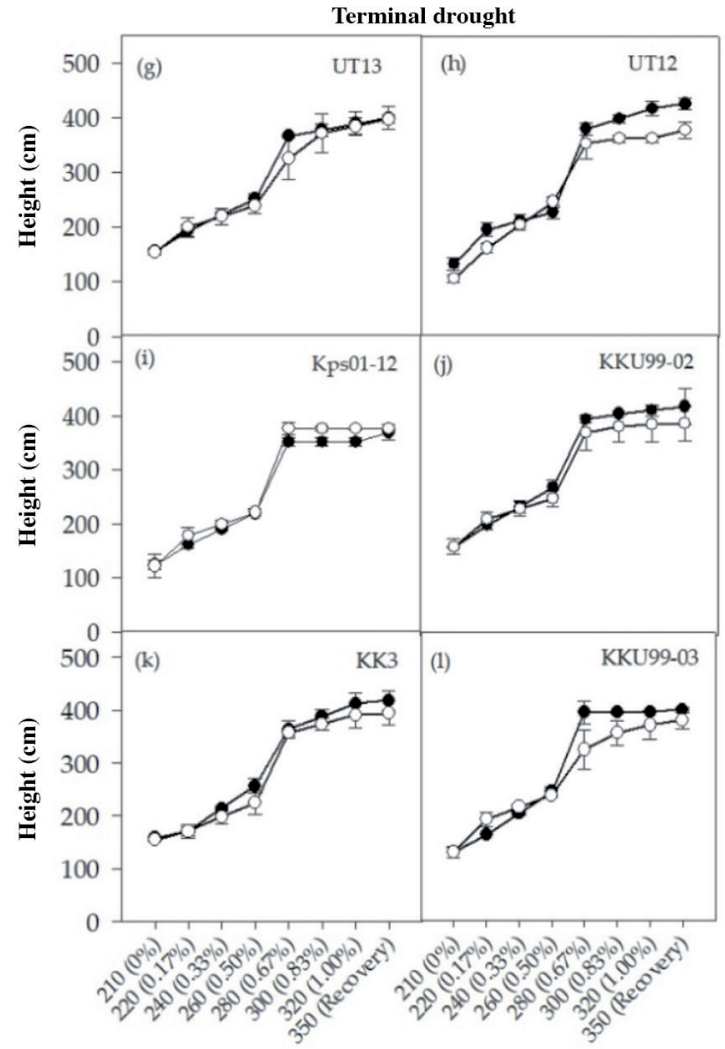

Days after planting

Control treatment $\rightarrow \sim$ PEG treatment

Vertical bars show the standard error of the differences of means.

For another group, insensitive in terms of shoot mass, there were variations of responses in the traits. 'Kps01-12' had no reduction of shoots under early drought conditions, similar to 'KKU99-03' (Figure 3g); however, this genotype had acclimation of root maintenance against water uptake limitations (Figure 3i). Consequently, 'Kps01-12' can maintain transpiration represented by stomatal conductance (Figure 7b). Even with lower height values under the recovery phase, this genotype compensated for shoot mass via increasing the number of tillers. Moreover, 'KK3' had a good performance for partitioning of assimilates under early drought in pot conditions (Khonghintaisong et al., 2018), and it also had good adaptations for root and shoot parts under a hydroponic system. A small shoot size was found in 'KK3' during osmotic stress, but enhancement of roots (Figure 3i) and maintenance of green leaf numbers are good adaptations to drought (Figure 6b). However, in the recovery phase, 'KK3' could provide more proportions of food from photosynthesis to shoots and less to roots. Thus, for the 'KK3' genotype, stalk and leaf dry weights can increase rapidly (Figure 3d, and 3f).

The remaining lines such as 'KK3', 'UT13' and 'KKU99-02' can maintain shoot dry weights after recovery from early drought (Figure $3 \mathrm{~h}$ ). Leaf and stalk DM of these three cultivars decreased during the osmotically-stressed period (Figure $3 \mathrm{c}$ and $3 \mathrm{e}$ ), whereas height of stalks after recovery did not differ from normal conditions (Figure 5a, 5d, and 5e). For physiology, low reductions of green leaf numbers were found in 'UT13' and 'KKU99-02', despite water limitations significantly reducing green leaf number in 'KK3' (Figure 6b), meanwhile assimilate could be maintained via a high rate of C fixation from photosynthesis (Figure 7a). 
Figure 6. Number of brown and green leaves of six sugarcane cultivars under hydroponic system, with control treatments (a), polyethylene glycol (PEG) $1.00 \%$ (b), and 60 DAR of control treatments (c), and 60 DAR of PEG treatment (d).

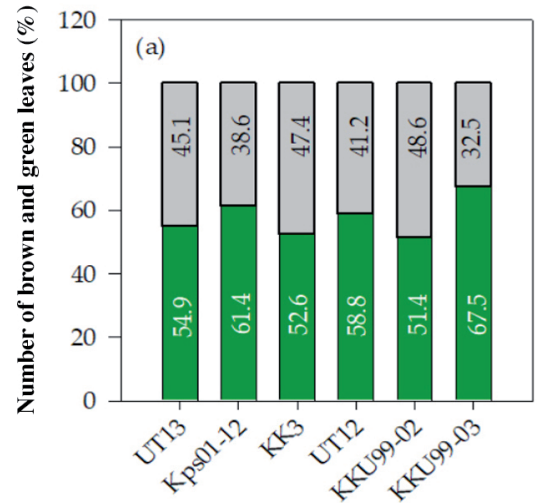

Control treatment

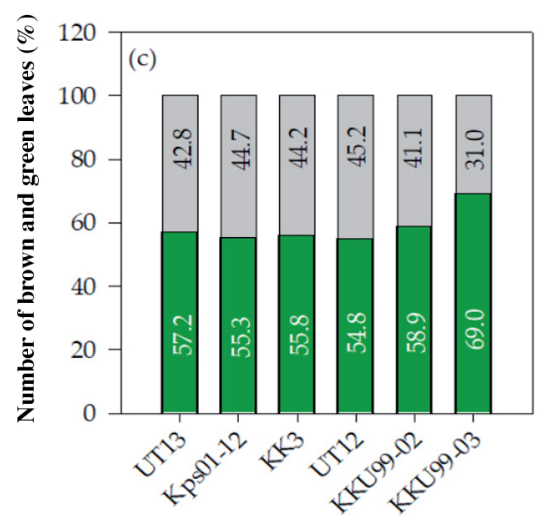

60 DAR of control treatment

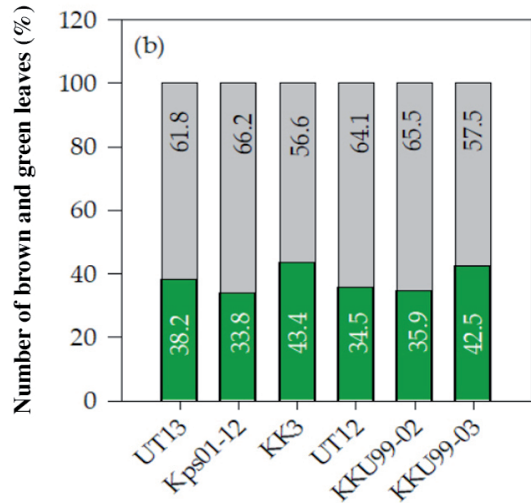

PEG $1.00 \%$

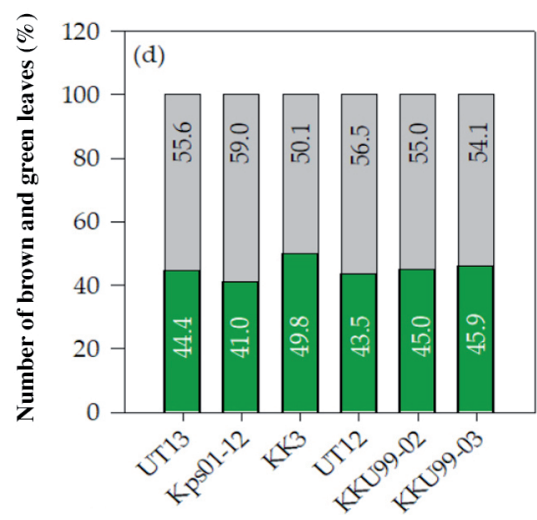

60 DAR of PEG treatment

Number of green leaves (\%)

$\square$ Number of brown leaves (\%)

DAR: Days after recovery.

Vertical bars show standard error difference of means and mean value with the same letters are nonsignificantly different by LSD at $\mathrm{p}<0.05$.

Figure 7. Photosynthesis rate (a) and stomatal conductance (b) of six sugarcane cultivars under hydroponic system, with polyethylene glycol (PEG) and control treatments.

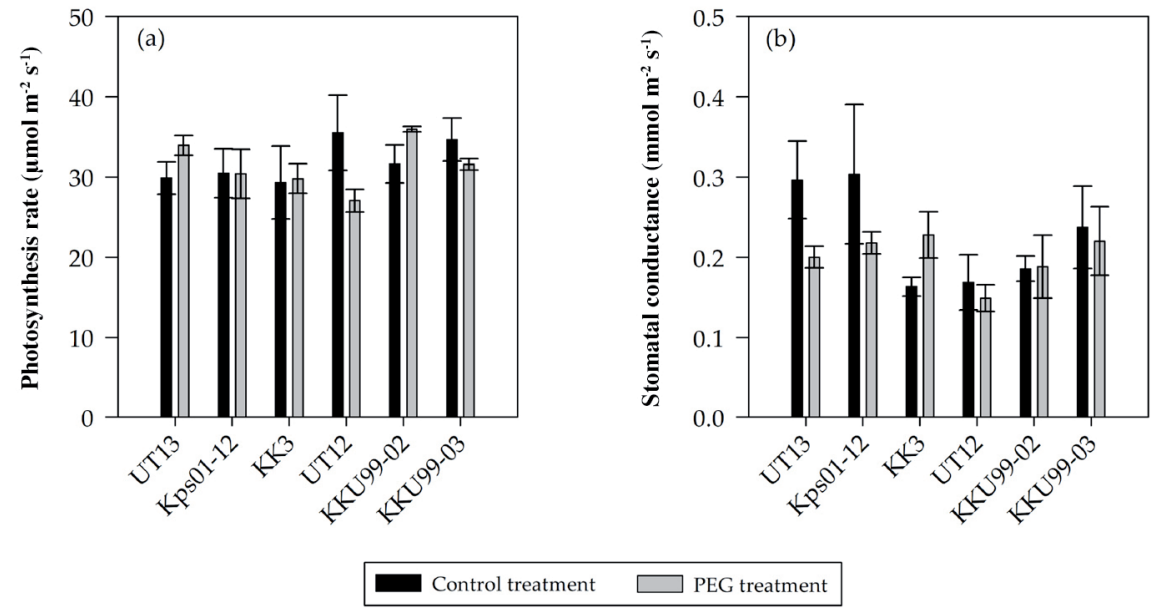

Vertical bars show the standard error of the differences of means. 
However, there were no clear outcomes for the response of physiological and morphological characteristics when subjected to terminal drought. It seems likely that drought stress in the late season would slightly affect sugarcane because it is at almost the physiological maturity stage.

\section{CONCLUSIONS}

Drought mechanism clearly only showed water deficits at early growth stages, but not terminal drought stress. All genotypes had reduced leaf water potential (LWP) values with water availability limitations of the media solution, and then recovery to normal values when the stress was removed. The six sugarcane cultivars used in this study could be classified into two groups based on the responses of shoot mass after experiencing early drought, consisting of reduced shoot dry weight when exposed to early drought stress and insensitive to early drought stress. The shoot-reduced cultivar responded to early drought in hydroponics by reducing root dry weight and the proportion of green leaves number. However, the drought resistance mechanisms that can maintain aboveground dry matter of sugarcane cultivars in this condition responded variously. The good adaptations of the traits supporting shoot mass maintenance under hydroponics were photosynthesis, stomatal conductance, partitioning of dry weight, root dry weights and green leaf number proportions. The ability to perform acclimation of these traits might be useful for improving drought resistance genotypes in the future.

\section{ACKNOWLEDGEMENTS}

Grateful acknowledgement is made to Northeast Thailand Cane and Sugar Research Center, Faculty of Agriculture, Khon Kaen University, Thailand Research Fund The research was funded in part by the Government of Thailand's Grants to Khon Kaen University (KKU; FY2019).

\section{REFERENCES}

Amist, S.N., and Singh, N.B. 2016. PEG imposed water deficit and physiological alterations in hydroponic cabbage. Iranian Journal of Plant Physiology 6(2):1651-1658.

Ayalew, H., Ma, X., and Yan, G. 2015. Screening wheat (Triticum spp.) genotypes for root length under contrasting water regimes: potential sources of variability for drought resistance breeding. Journal of Agronomy and Crop Science 201:189-194

Begum, M.K., Alam, M.R., Islam, M.S., and Arefin, M.S. 2012. Effect of water stress on physiological characters and juice quality of sugarcane. Sugar Tech 14(2):161-167.

Chapae, C., Songsri, P., and Jongrungklang, N. 2019. Hydroponics: An alternative method for root and shoot classification on sugarcane genotypes. AGRIVITA Journal of Agricultural Science 41(2):350-362.

Endres, L., dos Santos, C.M., de Souza, G.V., Menossi, M., and dos Santos, J.C.M. 2018. Morphological changes recorded in different phenophases of sugarcane plants subjected to water stress in tropical field conditions. Australian Journal of Crop Science 12(07):1041-1050

García-Morales, S., Trejo-Téllez, L.I., Gómez-Merino, F.C., Espinosa-Victoria, D., Herrera-Cabrera, E.B., Tavitas-Fuentes, L., et al. 2012. Physiological response of rice plants growing under osmotic stress in hydroponics. II International Symposium on Soilless Culture and Hydroponics. Acta Horticulturae 947:401-408.

Gashgari, R., Alharbi, K., Mughrbil, K., Jan, A., and Glolam, A. 2018. Comparison between growing plants in hydroponic system and soil based system. Proceedings of the $4^{\text {th }}$ World Congress on Mechanical, Chemical, and Material Engineering (MCM'18), Madrid, Spain. 16-18 August. Paper ICMIE Nr 131. International Conference on Measurement Instrumentation and Electronics (ICMIE)

Girdthai, T., Jogloy, S., Ketmala, T., Vorasoot, N., Akkasaeng, C., Wongkaew, S., et al. 2010. Relationship between root characteristics of peanut in hydroponics and pot studies. Crop Science 50:159-167.

Gomez, K.A., and Gomez, A.A. 1984. Statistical procedures for agricultural research. $2^{\text {nd }}$ ed. Wiley, New York, USA.

Hellal, F.A., El-Shabrawi, H.M., Abd El-Hady, M., Khatab, I.A., El-Sayed, S.A.A., and Abdelly, C. 2018. Influence of PEG induced drought stress on molecular and biochemical constituents and seedling growth of Egyptian barley cultivars. Journal of Genetic Engineering and Biotechnology 16:203-212.

Jaiphong, T., Tominaga, J., Watanabe, K., Nakabaru, M., Takaragawa, H., Suwa, R., et al. 2016. Effects of duration and combination of drought and flood conditions on leaf photosynthesis, growth and sugar content in sugarcane. Plant Production Science 427-437. 
Jangpromma, N., Thammasirirak, S., Jaisil, P., and Songsri, P. 2012. Effects of drought and recovery from drought stress on above ground and root growth, and water use efficiency in sugarcane (Saccharum officinarum L.) Australian Journal of Crop Science 6(8):1298-1304.

Khonghintaisong, J., Songsri, P., Toomsan, B., and Jongrungklang, N. 2018. Rooting and physiological trait responses to early drought stress of sugarcane cultivars. Sugar Tech 20:396-406.

Larkunthod, P., Nounjan, N., Siangliw, J.L., Toojinda, T., Sanitchon, J., Jongdee, B., et al. 2018. Physiological responses under drought stress of improved drought tolerant rice lines and their parents. Notulae Botanicae Horti Agrobotanici Cluj-Napoca 46(2):679-687.

Medeiros, D.B., da Silva, E.C., Nogueira, R.J.M.C., Teixeira, M.M., and Buckeridge, M.S. 2013. Physiological limitations in two sugarcane varieties under water suppression and after recovering. Theoretical and Experimental Plant Physiology 25(3):213-222.

Meher, P., Shivakrishna, K., Ashok Reddy, D., and Rao, M. 2017. Effect of PEG-6000 imposed drought stress on RNA content, relative water content (RWC), and chlorophyll content in peanut leaves and roots. Saudi Journal of Biological Sciences 25:285-289.

Nguyen, N.T., McInturf, S.A., and Mendoza-Cózatl, D.G. 2016. Hydroponics: A versatile system to study nutrient allocation and plant responses to nutrient availability and exposure to toxic elements. Journal of Visualized Experiments $113: \mathrm{e} 54317$.

O’Donnell, N.H., Moller, B.L., Neale, A.D., Hamill, J.D., Blomstedt, C.K., and Gleadow, R.M. 2013. Effects of PEG-induced osmotic stress on growth and dhurrin levels of forage sorghum. Plant Physiology and Biochemistry 73:83-92.

Ogbonnaya, C.I., Sarr, B., Brou, C., Diouf, O., Diop, N.N., and Roy-Macauley, H. 2003. Selection of cowpea genotypes in hydroponics, pots, and field for drought tolerance. Crop Science 43:1114-1120.

Ohashi, Y., Nakayama, N., Saneoka, H., Mohapatra, P.K., and Fujita, K. 2008. Differences in the responses of stem diameter and pod thickness to drought stress during the grain filling stage in soybean plants. Acta Physiologiae Plantarum 31:271-277.

Patade, V.Y., Bhargava, S., and Suprasanna, P. 2011. Salt and drought tolerance of sugarcane under iso-osmotic salt and water stress: growth, osmolytes accumulation, and antioxidant defense. Journal of Plant Interactions 6:275-282.

Rajkumar, S., and Ibrahim, S.M. 2014. In vitro hydroponic studies on root characters for drought resistance assessment in rice. American-Eurasian Journal of Agricultural \& Environmental Sciences 14(5):396-400.

Ramesh, P., and Mahadevaswamy, M. 2000. Effect of formative phase drought on different classes of shoots, shoot mortality, cane attributes, yield and quality of four sugarcane cultivars. Journal of Agronomy \& Crop Science 185:249-258.

Raziuddin Swati, Z.A., Bakht, J., Farhatullah Ullah, N., Shafi, M., et al. 2010. In situ assessment of morpho-physiological response of wheat (Triticum aestivum L.) genotypes to drought. Pakistan Journal of Botany 42(5):3183-3195.

Robin, A.H.K., Uddin, M.J., and Bayazid, K.N. 2015. Polyethylene glycol (PEG)-treated hydroponic culture reduces length and diameter of root hairs of wheat varieties. Agronomy 5:506-518.

Shavrukov, Y., Genc, Y., and Hayes, J. 2012. The use of hydroponics in abiotic stress tolerance research. p. 39-66. In Asao, T. (ed.) Hydroponics - A standard methodology for plant biological researches. InTech, Rijeka, Croatia.

Silva, M.A., Jifon, J.L., Sharma, V., da Silva, J.A.G., Caputo, M.M., Damaj, M.B., et al. 2011. Use of physiological parameters in screening drought tolerance in sugarcane genotypes. Sugar Tech 13(3):191-197.

Singh, S., and Gururaja Rao, P.N. 1987. Varietal differences in growth characteristics in sugar cane. Journal of Agricultural Science 108:245-247.

Smit, M.A., and Singels, A. 2006. The response of sugarcane canopy development to water stress. Field Crops Research 98:91-97.

Smith, D.M., Inman-Bamber, N.G., and Thorburn, P.J. 2005. Growth and function of the sugarcane root system. Field Crops Research 92:169-183.

Taiz, L., and Zeiger, E. 2002. Plant physiology. $3^{\text {rd }}$ ed. 690 p. Sinauer Associates, Sunderland, Massachusetts, USA.

Trejo-Téllez, L.I., and Gómez-Merino, F.C. 2012. Nutrient solutions for hydroponic system. In Asao, T. (ed.) Hydroponics - a standard methodology for plant biological researches. InTech, Rijeka, Croatia.

Wahome,P.K., Oseni, T.O., Masarirambi, M.T., and Shongwe, V.D. 2011. Effects of different hydroponics systems and growing media on the vegetative growth, yield and cut flower quality of gypsophila (Gypsophila paniculata L.) World Journal of Agricultural Sciences 7(6):692-698.

Zhao, D., Glaz, B., and Comstock, J.C. 2012. Sugarcane leaf photosynthesis and growth characters during development of water-deficit stress. Crop Science 53:1066-1075. 